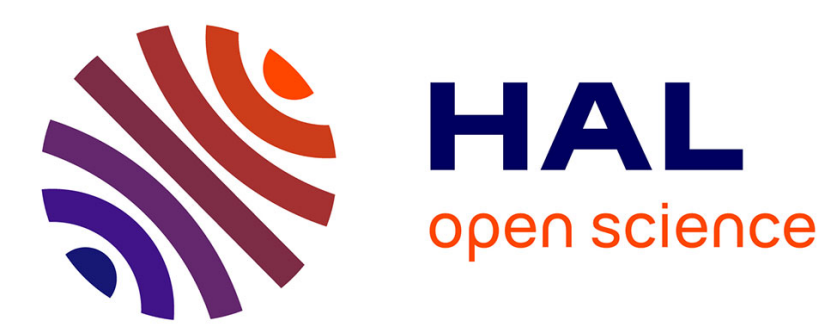

\title{
Confining Nitrogen Inversion to Yield Enantiopure Quinolino[3,2,1-k]Phenothiazine Derivatives
}

Cassandre Quinton, Lambert Sicard, Nicolas Vanthuyne, Olivier Jeannin, Cyril Poriel

\section{- To cite this version:}

Cassandre Quinton, Lambert Sicard, Nicolas Vanthuyne, Olivier Jeannin, Cyril Poriel. Confining Nitrogen Inversion to Yield Enantiopure Quinolino[3,2,1-k]Phenothiazine Derivatives. Advanced Functional Materials, 2018, 28 (39), pp.1803140. 10.1002/adfm.201803140 . hal-01902029

HAL Id: hal-01902029

https://hal-univ-rennes1.archives-ouvertes.fr/hal-01902029

Submitted on 7 Apr 2019

HAL is a multi-disciplinary open access archive for the deposit and dissemination of scientific research documents, whether they are published or not. The documents may come from teaching and research institutions in France or abroad, or from public or private research centers.
L'archive ouverte pluridisciplinaire HAL, est destinée au dépôt et à la diffusion de documents scientifiques de niveau recherche, publiés ou non, émanant des établissements d'enseignement et de recherche français ou étrangers, des laboratoires publics ou privés. 


\title{
Confining Nitrogen Inversion to Yield Enantiopure Quinolino[3,2,1-k]Phenothiazine Derivatives
}

\author{
Cassandre Quinton, Lambert Sicard, Nicolas Vanthuyne, Olivier Jeannin, \\ and Cyril Poriel*:
}

The first examples of optically pure $9 \mathrm{H}$-quinolino[3,2,1-k]phenothiazine (QPTZ)-based molecules are reported. The inversion of the nitrogen atom, locked in the QPTZ fragment, is confined with a high-energy barrier that has allowed the isolation at room temperature of each stereoisomer. Considering the growing necessity in molecular electronics to introduce chiral characteristics within highly efficient molecular fragments, a molecular strategy to generate enantiopure derivatives constructed on the very promising electron rich core QPTZ is provided. As this work aims to report the foundations of the QPTZ chirality, the present findings may open avenues towards the use of this fragment in its optically pure form.

\section{Introduction}

The incorporation of chirality in highly efficient molecular fragments is one of the chief future directions for all three types of organic electronics devices, ${ }^{[1]}$ namely organic lightemitting diodes (OLEDs), ${ }^{[2]}$ field effect transistors, ${ }^{[3]}$ and solar cells. ${ }^{[4]}$ The incorporation of a chiral compound in device can enable the detection and emission of chiral light or a enhance charge transport. ${ }^{[1]}$ However and despite recent promising studies, only a few examples have been reported to date. This is partly due to the limited number of chiral fragments displaying a high efficiency when incorporated in devices. Two years ago, a new electron rich core, 9H-quinolino[3,2,1-k]phenothiazine (QPTZ), has appeared in literature displaying its potential in the field of phosphorescent OLEDs..$^{[5]}$ This fragment consists of a phenylacridine core $e^{[6]}$ to which a sulfur bridge was added between the top and side phenyl rings. In this previous work, the crucial role played by this sulfur atom in the electronic properties (i.e., raising of the highest occupied

Dr. C. Quinton, L. Sicard, Dr. O. Jeannin, Dr. C. Poriel Univ Rennes

CNRS

ISCR-6226, F-35000 Rennes, France

E-mail: cyril.poriel@univ-rennes1.fr

Dr. N. Vanthuyne

Aix Marseille Univ

CNRS

Centrale Marseille

iSm2, Marseille F-13397, France molecular orbital level and of the spinorbit coupling) has been demonstrated. ${ }^{[5]}$ The QPTZ fragment incorporated in spiroconfigured materials has thus led to highly efficient blue phosphorescent OLEDs, displaying better performance than those obtained with the widely used phenylacridine. ${ }^{[5]}$ In the present work, we wish to focus on the dynamic behavior of the nitrogen atom in QPTZ-based molecules. Indeed, $N$-pyramidal amines with three different substituents attached to the nitrogen atom can be optically active if there is a thermodynamically predominant conformer in the conformational equilibrium, but the resulting conformers often cannot be isolated as the nitrogen inversion barrier is too low. ${ }^{[7]}$ In fact, for configurational stability to be observed, the nitrogen inversion energy barrier should be higher than $100 \mathrm{~kJ} \mathrm{~mol}^{-1}$ at room temperature. ${ }^{[8]}$ This value can be reached by inserting the nitrogen atom into a ring, adding strain in the planar transition state..$^{[9]}$ Interestingly, in the rigid QPTZ fragment investigated herein, the confinement of the nitrogen atom within a dissymmetric bridged structure increases the energy of this inversion barrier which therefore enables the isolation of the resulting isomers. Moreover, the sulfur atom seems to contribute to the structural and chiral characteristics described herein. Indeed, the sulfur/carbon linkage rigidifies the system compared to the phenylacridine fragment but retains enough flexibility, unlike indoloacridine, ${ }^{[10]}$ to allow the inversion of the nitrogen atom when heated. Note that a structurally related analogue possessing an oxygen atom instead of the sulfur atom has been reported with nevertheless no mention of nitrogen inversion. ${ }^{[11]}$ Thus, this work presents our investigations on the nitrogen inversion of the QPTZ fragment and the first examples of optically pure QPTZ-based molecules (1-3, Figure 1) described in literature. Constraining the nitrogen atom in a pyramidal configuration at room temperature appears hence as an efficient strategy to generate enantiopure compounds. Furthermore, the spiro carbon of spirofluorene-based compounds also allows the introduction of chirality in such systems. ${ }^{[12]}$

Three molecular models based on the fluorene-spiro-QPTZ (F-s-QPTZ) architecture have been chosen for this study: the unsubstituted F-s-QPTZ (2) and two substituted F-s-QPTZ possessing different substitution patterns (1 and $\mathbf{3}$ ) in order to investigate the impact of the steric hindrance on the nitrogen inversion. Considering electronic device applications for the QPTZ core, it is important to know whether the inversion of 
a)<smiles>c1ccc(N2c3ccccc3-c3ccccc3C23c2ccccc2Sc2ccccc23)cc1</smiles>

1

b)<smiles></smiles>

2

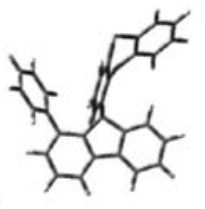

$1 \mathrm{~N}_{\mathrm{R}} \mathrm{C}_{\mathrm{S}}$

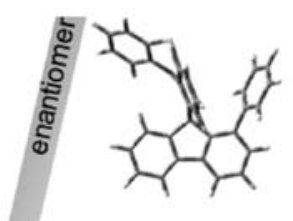

$1 \mathrm{~N}_{\mathrm{S}} \mathrm{C}_{\mathrm{R}}$

c)

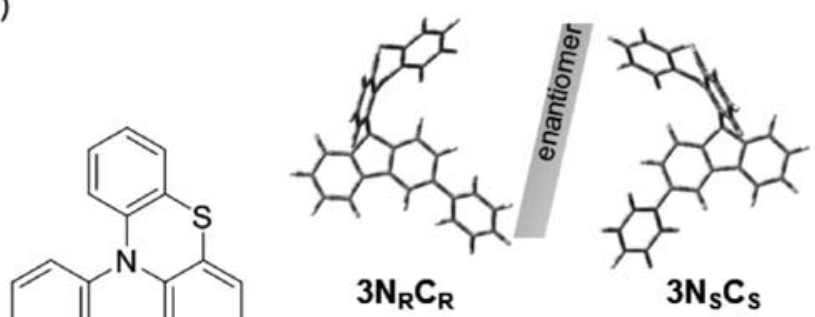

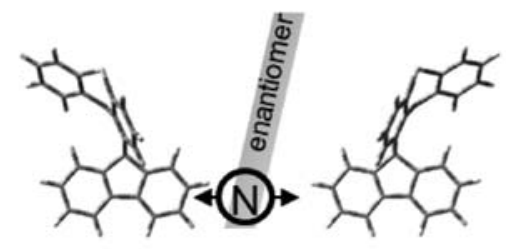

$2 \mathrm{~N}_{\mathrm{S}}$

$2 \mathrm{~N}_{\mathrm{R}}$<smiles>CC1(C)c2ccccc2-c2cc(P)ccc21</smiles>

3

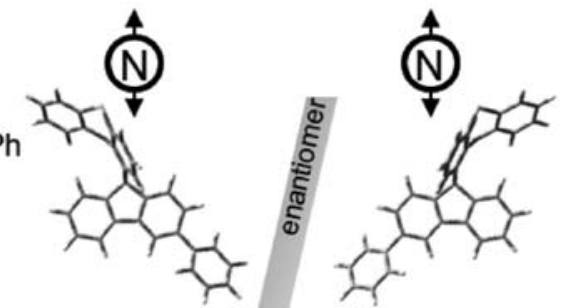

$3 \mathrm{~N}_{\mathrm{S}} \mathrm{C}_{\mathrm{R}}$

$3 \mathrm{~N}_{\mathrm{R}} \mathrm{C}_{\mathrm{S}}$

\section{$\mathrm{N}_{\mathrm{R}} \stackrel{\mathrm{N}}{\longrightarrow} \mathrm{N}_{\mathrm{S}}$ : nitrogen inversion}

Figure 1. Molecular structures of the investigated molecules. a) 1, b) 2, and c) 3 and their relationships obtained by molecular modelling (optimized structures with b3lyp $/ 6-31 \mathrm{~g}(\mathrm{~d}))$. The view angle chosen to highlight the phenothiazine flip shows the two phenyl rings of the acridine moiety and the two sigma bonds of the spiro bridge as superimposed (different views of $\mathbf{2} \mathbf{N}_{\mathrm{R}}$ can be found Figure $\mathbf{S} 48$ in the Supporting Information). Sulfur atom in yellow and nitrogen atom in blue.

the nitrogen atom can occur or not and, if it can, how quickly and at which temperature.

\section{Results and Discussion}

Compounds 1-3 were readily obtained through a short and efficient synthetic approach by coupling the halogeno-aryl 10-(2-bromophenyl)-10H-phenothiazine (obtained from the copper catalysed Goldberg coupling of phenothiazine and 2-bromoiodobenzene), with the corresponding 9-fluorenone: 1-phenyl-9-fluorenone for 1, 9-fluorenone for 2, 3-phenyl9-fluorenone for 3 (Scheme 1). The corresponding fluorenols were not isolated and were involved in an intramolecular electrophilic cyclisation reaction to give the three targets $1-3$ in good yields.

After synthesis, the ${ }^{1} \mathrm{H}$ and ${ }^{13} \mathrm{C}$ NMR spectra of the three compounds 1-3 provide the first piece of interesting data (see Figures S49-S68 in the Supporting Information). Indeed, 3 displays a complex spectrum, characteristic of a mixture of diastereoisomers, very different to that of the unsubstituted 2 and that of the 1 -substituted 1.
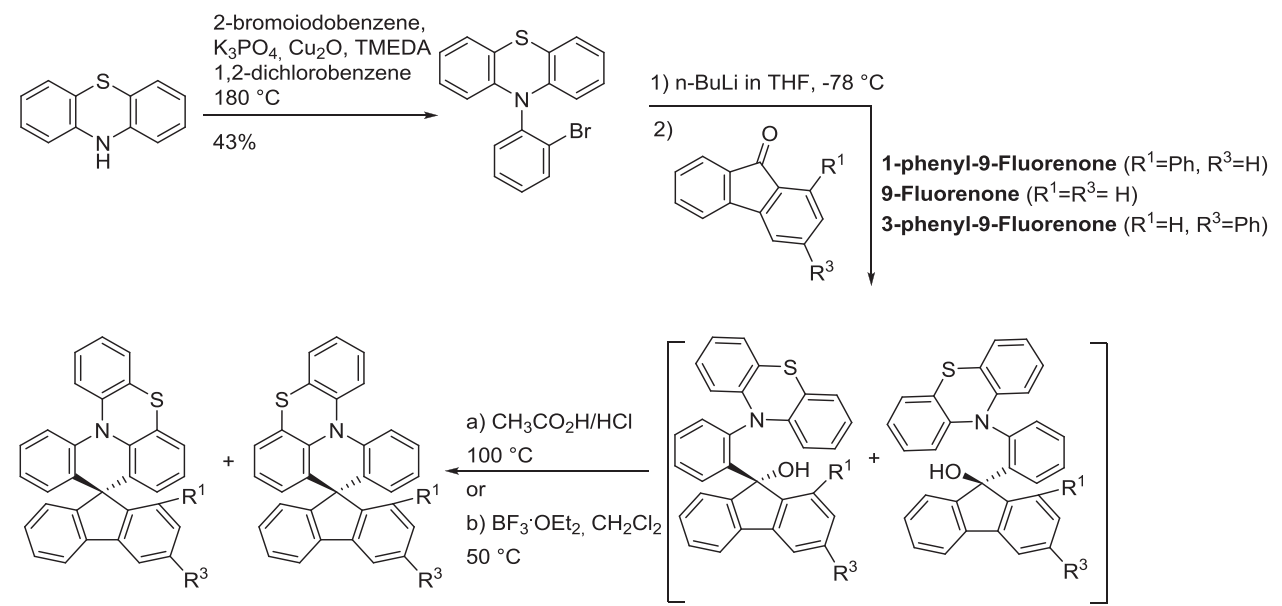

1: $R^{1}=P h, R^{3}=H(75 \%, 2$ steps, via a $)$

2: $R^{1}=R^{3}=H(52 \%, 2$ steps, via a)

3: $\mathrm{R}^{1}=\mathrm{H}, \mathrm{R}^{3}=\mathrm{Ph}(77 \%, 2$ steps, via $b)$

Scheme 1. Syntheses of compounds 1-3. 
The presence of diastereoisomers in 3 suggests at least two stereogenic centers, identified in our case as the nitrogen atom and the spiro carbon (the fluorene being dissymmetrical). These stereochemical features have been confirmed by chiral high pressure liquid chromatography (HPLC) studies (see Figures S2, S4, and S6 in the Supporting Information), which have allowed to separate and isolate each diastereoisomer of 3: $3 N_{R} C_{R}, 3 N_{S} C_{S}, 3 N_{R} C_{S}$, and $3 N_{S} C_{R}$ (Figure 1c).

$\mathrm{X}$-Ray crystallography of the two diastereoisomers $3 \mathrm{~N}_{\mathrm{S}} \mathrm{C}_{\mathrm{S}}$ and $3 \mathrm{~N}_{\mathrm{R}} \mathrm{C}_{\mathrm{S}}$ (Figure $2 \mathrm{c}$ ) clearly confirms the inversion of the nitrogen atom in the QPTZ fragment, which is caused by a flip of the a)

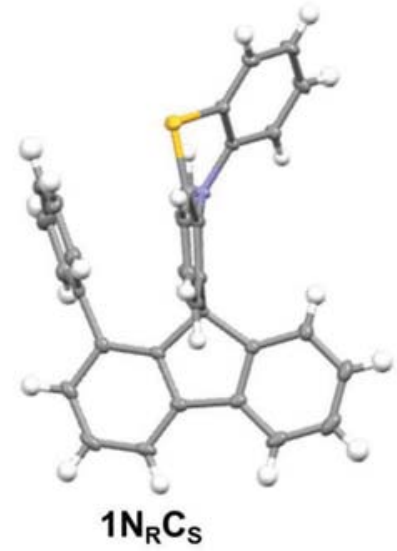

b)

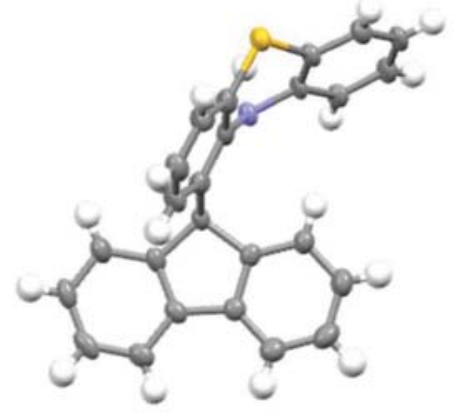

$2 \mathrm{~N}_{\mathrm{R}}$

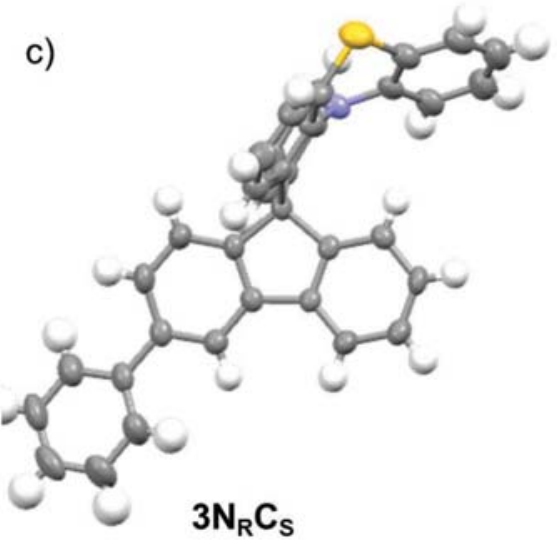

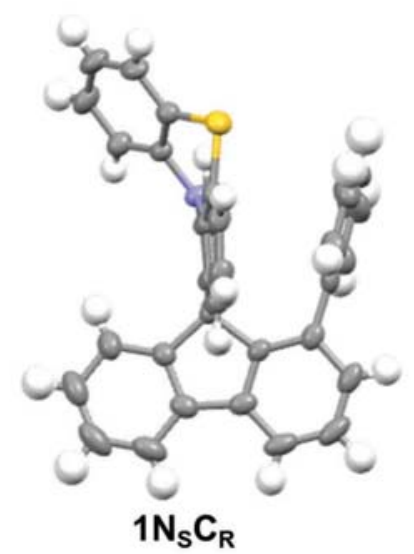

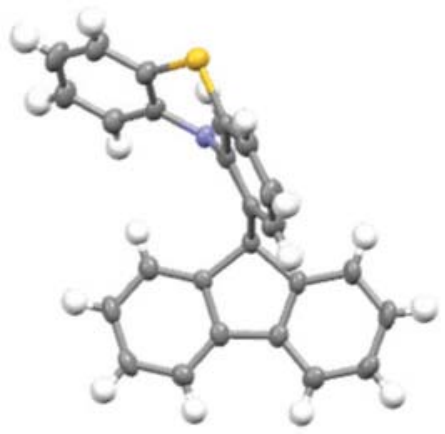

$2 \mathrm{~N}_{S}$

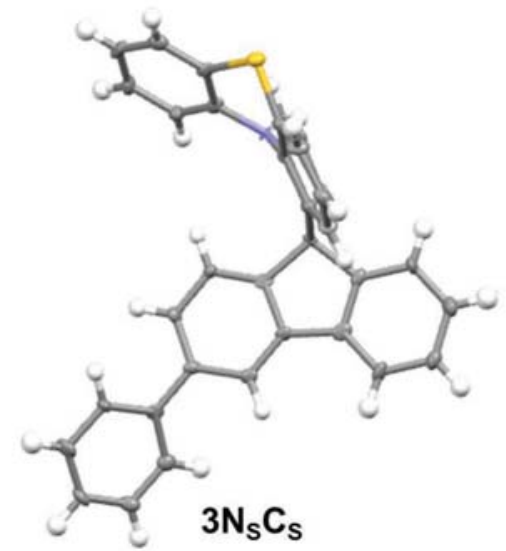

Figure 2. X-ray structures of a) $1 N_{R} C_{S}$ and $1 N_{S} C_{R}$, b) $2 N_{R}$ and $2 N_{S}$, and c) $3 N_{R} C_{S}$ and $3 N_{S} C_{S}$. The view angle chosen to highlight the phenothiazine flip shows the two phenyl rings of the acridine moiety and the two sigma bonds of the spiro bridge as superimposed. Sulfur atom in yellow and nitrogen atom in blue. phenothiazine core. Indeed, the QPTZ moiety is not flat due to the intense deformations induced by the phenothiazine and acridine cores (Figure 2). In fact, the nitrogen atom is pyramidal with values of nitrogen torsion angle found between $157^{\circ}$ for $3 \mathrm{~N}_{R} \mathrm{C}_{\mathrm{S}}$ and $3 \mathrm{~N}_{\mathrm{S}} \mathrm{C}_{\mathrm{R}}$ and $162^{\circ}$ for $3 \mathrm{~N}_{\mathrm{S}} \mathrm{C}_{\mathrm{S}}$ (see Figure $\mathrm{S} 17$ and Table $\mathrm{S} 3$ in the Supporting Information), as expected for nitrogen with one or more aromatic substituents. ${ }^{[13]}$ This shows that the trivalont compounds is in an intermediate hybridization state between $\mathrm{sp}^{2}$ and $\mathrm{sp}^{3}$. Thus, the phenothiazine can move from one side of the fluorene to the other through a structural reorganization of the acridine, much like a wing flapping. The same kind of stereoisomers would have been expected for 1 which displays the same two stereogenic centres. However, only two stereoisomers (enantiomers) have been isolated by chiral HPLC: $\mathbf{1 N}_{\mathrm{R}} \mathrm{C}_{\mathrm{S}}$ and $1 \mathrm{~N}_{\mathrm{S}} \mathrm{C}_{\mathrm{R}}$ (Figures 1a and 2a). Indeed, the steric hindrance induced by the pendant phenyl ring in position 1 of the fluorene prevents the flipping of the phenothiazine above discussed and hence the formation of the other pair of enantiomers. This structural feature provides an efficient diastereocontrol and can be easily visualized on the X-ray structures of the two enantiomers $1 \mathbf{N}_{\mathrm{R}} \mathrm{C}_{\mathrm{S}}$ and $\mathbf{1 N}_{\mathrm{S}} \mathbf{C}_{\mathrm{R}}$ (Figure 2a). The phenyl ring in $\mathrm{C} 1$ displays two important characteristics. First, it is almost orthogonal to the fluorene with a dihedral angle between the mean plane of the phenyl ring in $\mathrm{C} 1$ and that of the fluorene of $83.3^{\circ}$ for $1 N_{R} C_{S}$ and of $84.1^{\circ}$ for $1 N_{S} C_{R}$ suggesting a strongly sterically hindered environment (see Figures S13 and S14 in the Supporting Information). This structural characteristic is at the origin of the emergence of one-substituted fluorenes recently reported in literature. ${ }^{[14]}$ In addition, the pendant phenyl ring is very close to the QPTZ fragment (three $\mathrm{C} / \mathrm{C}$ intramolecular distances are indeed shorter than the sum of the Van der Walls radii, see Figures S15 and S16 in the Supporting Information).

Finally, the case of 2 provides a different example. For this molecule, in which the unsubstituted fluorene is symmetrical, the only stereogenic centre is the nitrogen atom. This feature, clearly observed in the $\mathrm{X}$-ray structure of the racemic mixture of 2 leads to two enantiomers $2 \mathrm{~N}_{\mathrm{S}}$ and $2 \mathrm{~N}_{\mathrm{R}}$ (Figure 2b), which have been successfully isolated by chiral HPLC (see Figure S2 in the Supporting Information). The assignment of the absolute stereochemistry was performed for each enantiomer of $\mathbf{1}$ and 3 by crystallography (Figure 2a,c and see Figures S7-S10,S12 and Tables S1-S2 in the Supporting Information) and confirmed by the comparison of experimental and theoretical circular dichroism (CD) spectra (see 
Figures S31-S33 in the Supporting Information). In the case of $2 \mathrm{~N}_{\mathrm{S}}$ and $2 \mathrm{~N}_{\mathrm{R}}$, the stereochemistry has been assigned, thanks to their CD spectra (Figure 3).

These spectra are mirror images of each other and in good coherence between experimental and theoretical studies. The CD spectrum of $2 \mathrm{~N}_{\mathrm{S}}\left(2 \mathrm{~N}_{\mathrm{R}}\right)$ displays i) a small negative (positive) band at $357 \mathrm{~nm}$, ii) a small positive (negative) band at $325 \mathrm{~nm}$, iii) an intense negative (positive) band at $268 \mathrm{~nm}$, iv) an intense positive (negative) band at $251 \mathrm{~nm}, \mathrm{v}$ ) a small negative (positive) band at $225 \mathrm{~nm}$, and vi) an intense negative (positive) band at $203 \mathrm{~nm}$ (Figure 3).

To sum up, compound 2 displays only the nitrogen atom as stereogenic center (and thus two enantiomers), 3 displays both the spiro carbon and the nitrogen atom as stereogenic centers (leading to two pairs of enantiomers and thus four diastereoisomers) and finally 1 also displays both stereogenic centers but leading to only one pair of enantiomers due to the steric

a)

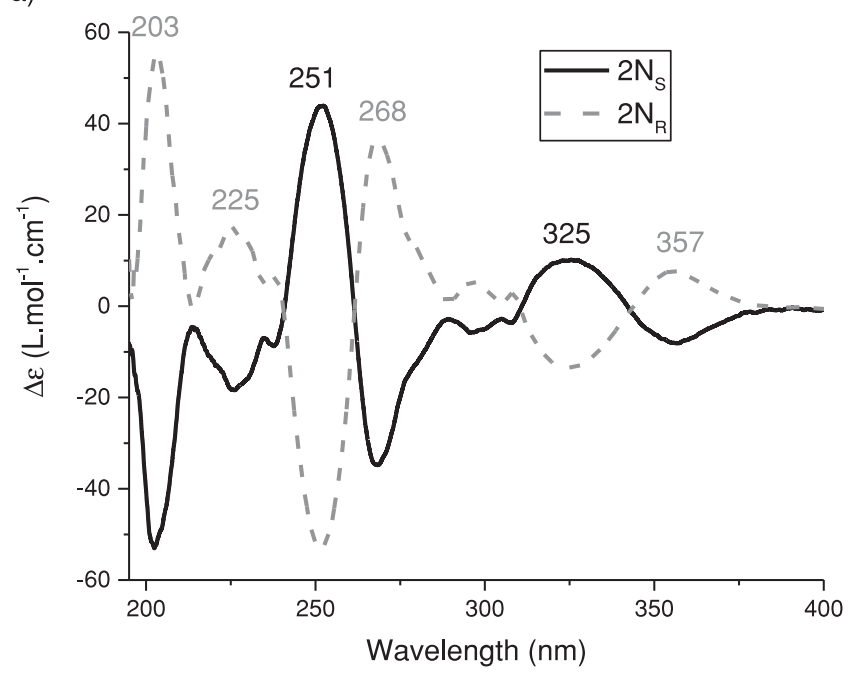

b)

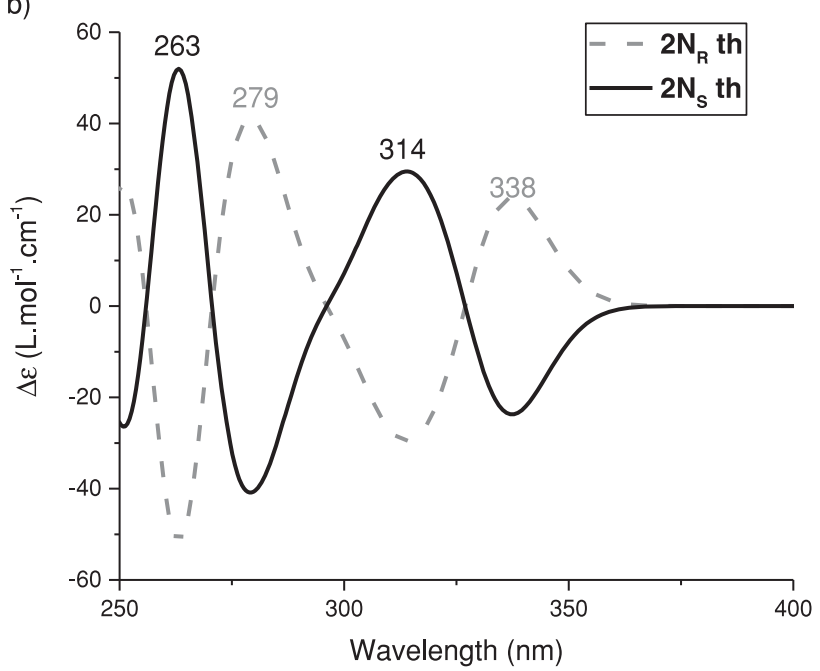

Figure 3. a) Experimental $\left(\mathrm{CH}_{3} \mathrm{OH}\right.$ at $\left.298 \mathrm{~K}\right)$ and b) theoretical (timedependent density functional theory (TD-DFT), PBE0/6-311+g(d,p)) circular dichroism spectra of enantiomers $2 \mathrm{~N}_{S}$ and $2 \mathrm{~N}_{\mathrm{R}}$. hindrance induced by the presence of the phenyl ring in position 1. Finally, it should be stressed that 1-3 present the same electronic properties.

The key feature of this work is related to the nitrogen inversion energy barrier in the constrained structure of the QPTZ fragment, which is high enough to enable the isolation at room temperature of the different stereoisomers of the presented compounds. In order to evaluate this barrier, the mechanism of the nitrogen inversion has been studied by a combination of experimental (NMR and HPLC) and theoretical techniques. Thus, the kinetic investigations of the nitrogen inversion of $3 N_{R} C_{R}$ into its diastereoisomer $3 N_{S} C_{R}$ have been first performed by measuring through chiral HPLC the evolution of the concentration of a solution of $3 \mathrm{~N}_{\mathrm{R}} \mathrm{C}_{\mathrm{R}}$ in ethanol over time at $351.15 \mathrm{~K}$ (Figure 4a).

This study gives a kinetic constant $k_{1}$ of $0.0029 \mathrm{~min}^{-1}$, a free energy of activation $\Delta G^{\neq}$of $115.5 \mathrm{~kJ} \mathrm{~mol}^{-1}$ (calculated from the Eyring equation, see Table S7 in the Supporting Information) and a half-life of inversion $t_{1 / 2}$ of $112 \mathrm{~min}$ for the $\mathrm{N}$ inversion from $3 N_{R} C_{R}$ to $3 N_{S} C_{R}$ (Table 1). Note that the conformer $3 N_{R} C_{R}$ is slightly more stable than its diastereoisomer $3 \mathrm{~N}_{S} \mathrm{C}_{R}$, with an energy difference of $0.4 \mathrm{~kJ} \mathrm{~mol}^{-1}$, value in accordance with that found by calculations $\left(0.4 \mathrm{~kJ} \mathrm{~mol}^{-1}\right.$, see below).

Kinetic investigations have also been performed through ${ }^{1} \mathrm{H}$ NMR studies (Figure 5). Indeed, the acridine protons in $\beta$ positions of the spiro carbon (Ha/Hb for $3 \mathrm{~N}_{R} \mathrm{C}_{\mathrm{R}}+3 \mathrm{~N}_{\mathrm{S}} \mathrm{C}_{\mathrm{S}}$ and $\mathrm{Hc}$ / Hd $3 N_{S} C_{R}+3 N_{R} C_{S}$ ) are sensitive to the nitrogen's configuration (Figure 5) and were used as efficient probes to determine the $\left[3 \mathrm{~N}_{\mathrm{R}} \mathrm{C}_{\mathrm{R}}+3 \mathrm{~N}_{\mathrm{S}} \mathrm{C}_{\mathrm{S}}\right] /\left[3 \mathrm{~N}_{\mathrm{S}} \mathrm{C}_{\mathrm{R}}+3 \mathrm{~N}_{\mathrm{R}} \mathrm{C}_{\mathrm{S}}\right]$ ratio. These signals are detected as doublets of doublets at 6.57 and 6.38 ppm respectively for $3 \mathrm{~N}_{S} \mathrm{C}_{R}$ and $3 \mathrm{~N}_{R} \mathrm{C}_{S}$ and 6.52 and 6.33 ppm for $3 \mathrm{~N}_{R} \mathrm{C}_{R}$ and $3 \mathrm{~N}_{\mathrm{S}} \mathrm{C}_{\mathrm{S}}$ with no overlap.

Thus, the decrease of the concentration $\left[3 \mathrm{~N}_{S} \mathrm{C}_{R}+3 \mathrm{~N}_{R} \mathrm{C}_{S}\right]$ in deuterated $N, N$-dimethylsulfoxide (DMSO- $d_{6}$ ) has been measured for the two protons $\mathrm{Hc}$ and $\mathrm{Hd}$ at five temperatures between 348 and $373 \mathrm{~K}$ (see Figures S22-S26 in the Supporting Information). At $348 \mathrm{~K}$, starting with $97 \%$ of $3 N_{S} C_{R}+3 N_{R} C_{S}$, the amount of their corresponding diastereoisomers $3 \mathrm{~N}_{\mathrm{R}} \mathrm{C}_{\mathrm{R}}+3 \mathrm{~N}_{\mathrm{S}} \mathrm{C}_{\mathrm{S}}$ gradually increases (15\% after $50 \mathrm{~min}, 35 \%$ after $200 \mathrm{~min}$ ) to reach $48 \%$ after $760 \mathrm{~min}$. Indeed, the final state is composed of $3 N_{S} C_{R}+3 N_{R} C_{S}$ at $48 \%$ and $3 N_{R} C_{R}+3 N_{S} C_{S}$ at $52 \%$ which corresponds to a stabilization of $0.3 \mathrm{~kJ} \mathrm{~mol}^{-1}$ for $3 \mathrm{~N}_{\mathrm{R}} \mathrm{C}_{\mathrm{R}}+3 \mathrm{~N}_{\mathrm{S}} \mathrm{C}_{\mathrm{S}}$ compared to $3 N_{S} C_{R}+3 N_{R} C_{S}$. This provides a kinetic constant $\mathrm{k}$ of $0.00275 \mathrm{~min}^{-1}$, a free energy of activation $\Delta G^{\neq}$of $114.6 \mathrm{~kJ} \mathrm{~mol}^{-1}$ at $348 \mathrm{~K}$ and a half-life of inversion $t_{1 / 2}$ of $132 \mathrm{~min}$ (from $3 \mathrm{~N}_{S} \mathrm{C}_{\mathrm{R}}+3 \mathrm{~N}_{\mathrm{R}} \mathrm{C}_{\mathrm{S}}$ to $3 \mathrm{~N}_{\mathrm{R}} \mathrm{C}_{\mathrm{R}}+3 \mathrm{~N}_{\mathrm{S}} \mathrm{C}_{\mathrm{S}}$ ).

The rate of inversion increases with the temperature. The resulting free energies are gathered in Table S8 in the Supporting Information for the five temperatures. The van't Hoff plot of $\ln \mathrm{K}$ versus $1 / \mathrm{T}$ gave us the enthalpy of activation of the inversion $\Delta H^{\neq}=106 \mathrm{~kJ} \mathrm{~mol}^{-1}$ and the entropy of activation of the inversion $\Delta S^{\neq}=-24 \mathrm{~J} \cdot \mathrm{mol}^{-1} \cdot \mathrm{K}^{-1}$ (Figure 6 and see Figure S27 and Table S9 in the Supporting Information). Thus, the free energy of activation $\Delta G^{\neq}$is found to be $113 \mathrm{~kJ} \mathrm{~mol}^{-1}$ at room temperature $(298 \mathrm{~K})$. This value being higher than $100 \mathrm{~kJ} \mathrm{~mol}^{-1},{ }^{[8]}$ it explains why all the isomers can be isolated at room temperature. Furthermore, we calculated a value of $\Delta G^{\neq}$of $114.9 \mathrm{~kJ} \mathrm{~mol}{ }^{-1}$ from $3 \mathrm{~N}_{\mathrm{R}} \mathrm{C}_{\mathrm{R}}$ at $315.15 \mathrm{~K}$, slightly lower than the one obtained by chiral HPLC studies in ethanol. The 

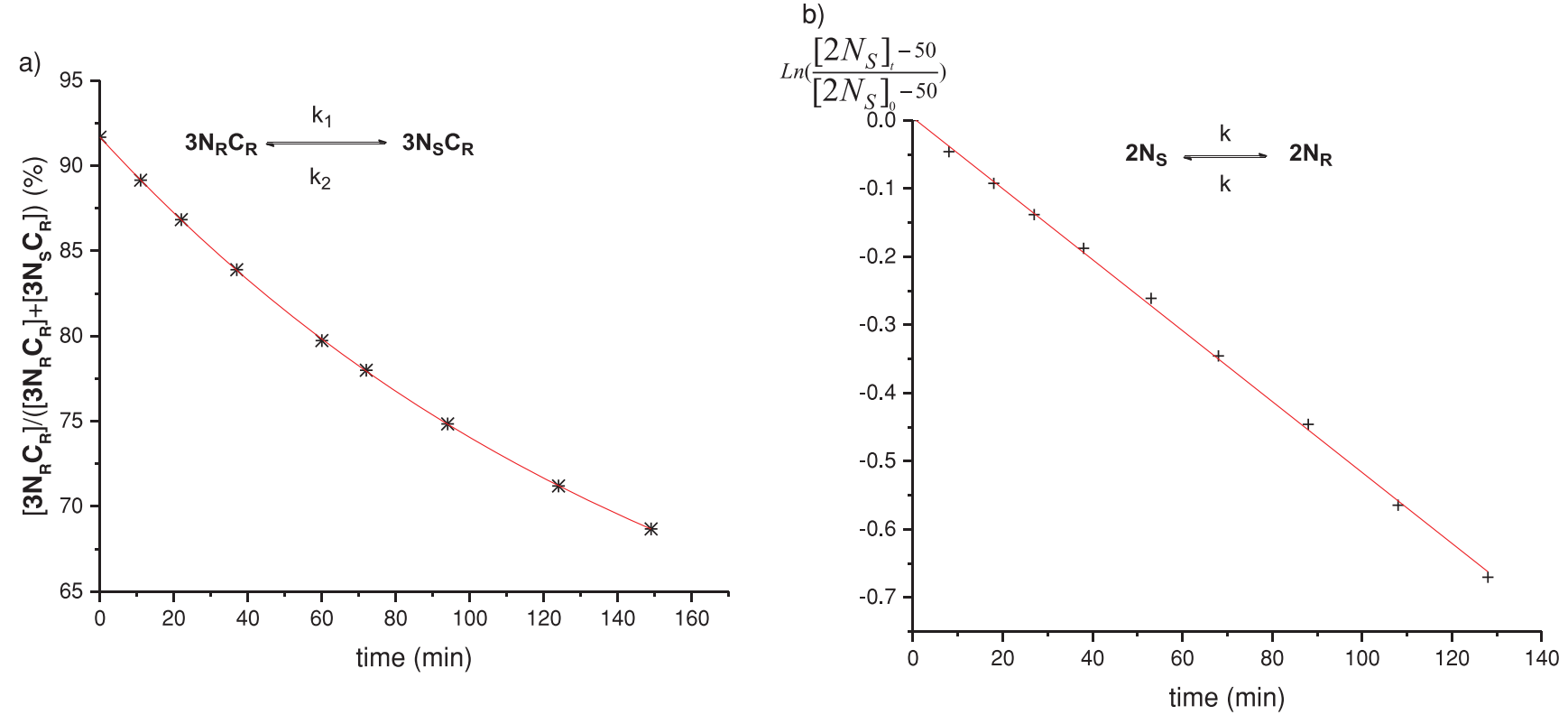

Figure 4. Evolution of the concentration of a) $3 N_{R} C_{R}$ or b) $2 N_{S}$ in ethanol through time at $351.15 \mathrm{~K}$.

nitrogen inversion barrier is therefore found to be higher in ethanol than in DMSO, which could be explained by a stabilization of the ground state through hydrogen bonding, even though this solvent effect seems weaker in our case than the ones reported in the literature. ${ }^{[7 a]}$ Furthermore, thermogravimetric analysis (TGA) investigations show decomposition temperatures, corresponding to a $5 \%$ mass loss, recorded between $572 \mathrm{~K}$ (for $3 \mathrm{~N}_{S} \mathrm{C}_{\mathrm{R}}+3 \mathrm{~N}_{\mathrm{R}} \mathrm{C}_{\mathrm{S}}$ ) and $587 \mathrm{~K}$ (for $3 \mathrm{~N}_{\mathrm{R}} \mathrm{C}_{\mathrm{S}}$ ) depending on the sample constitution (Figure S38, Supporting Information). Differential scanning calorimetry (DSC) does not allows us to determine the melting and the glass transition temperatures for each enantiopur form, because the nitrogen inversion begins at lower temperature than these characteristic temperatures (Figures S44-S47, Supporting Information).

Compound 1 displays a drastically different behavior. Indeed, the heating of 1 to $443 \mathrm{~K}$ leaves the ${ }^{1} \mathrm{H}$ NMR spectrum unchanged, clearly confirming that even with the help of thermal input the nitrogen inversion is impossible due to the steric hindrance induced by the phenyl ring in C1. Furthermore, TGA investigations of 1 and $1 \mathrm{~N}_{\mathrm{R}} \mathrm{C}_{\mathrm{S}}$ show decomposition temperatures of $548 \mathrm{~K}$ for the racemic mixture and

Table 1. Experimental thermodynamical data for the $\mathrm{N}$ inversion at $351.15 \mathrm{~K}$.

\begin{tabular}{lcccc}
\hline Compounds & $\Delta C^{\neq}\left[\mathrm{k} / \mathrm{mol}^{-1}\right]$ & $\mathrm{k}\left[\mathrm{min}^{-1}\right]$ & $t_{1 / 2}[\mathrm{~min}]$ & Solvent \\
\hline $\mathbf{2} \mathrm{N}_{\mathrm{R}}$ & $115.9^{\mathrm{a})}$ & 0.00260 & 133 & Ethanol \\
$\mathbf{3 N}_{\mathrm{R}} \mathrm{CR}$ & $115.5^{\mathrm{a})}$ & 0.00288 & 112 & Ethanol \\
& $114.9^{\mathrm{b})}$ & 0.00356 & 97 & DMSO- $d_{6}$ \\
${ }_{3} \mathrm{~N}_{\mathrm{S}} \mathrm{C}_{\mathrm{R}}$ & $115.1^{\mathrm{a})}$ & 0.00331 & 112 & Ethanol \\
& $114.6^{\mathrm{b})}$ & 0.00392 & 88 & DMSO- $d_{6}$ \\
\hline
\end{tabular}

a) HPLC measurements (in ethanol, $T=351.15 \mathrm{~K}$ ); b) Calculated $\Delta \mathrm{C}^{\neq}$at $351.15 \mathrm{~K}$ from the values of $\Delta H^{\neq}$and $\Delta S^{\neq}$obtained by NMR measurements in DMSO- $d_{6}$.
$579 \mathrm{~K}$ for the enantiopur $1 \mathrm{~N}_{\mathrm{R}} \mathrm{C}_{\mathrm{S}}$ (see Figure S37 in the Supporting Information). Thus, the packing mode seems to have an effect on the decomposition temperatures. Moreover, as the mass loss appears total around $633 \mathrm{~K}$ for both samples, we believe that the sublimation occurs at this temperature without a real decomposition of the compounds. DSC measurements were performed for both 1 and $1 \mathrm{~N}_{\mathrm{R}} \mathrm{C}_{\mathrm{S}}$ between 253 and $513 \mathrm{~K}$. At the first heating cycle (see Figures S40 and S41 in the Supporting Information), the two compounds present a sharp endothermic peak at 522 and $491 \mathrm{~K}$ respectively, associated with the melting of the two compounds ( $T_{\mathrm{m}}$ : 521 and $488 \mathrm{~K}$ respectively, determined from the peak onset). When both liquids were cooled down at the same rate from 513 to $253 \mathrm{~K}$, no recrystallization was detected; hence, the cooling leads to amorphous solids, which is highly beneficial for further device incorporation. At the second heating cycle, a glass transition phenomenon was observed at $378 \mathrm{~K}$ for 1 and at $377 \mathrm{~K}$ for $1 \mathrm{~N}_{\mathrm{R}} \mathrm{C}_{\mathrm{S}}\left(T_{\mathrm{g}}\right.$ : 376 and $374 \mathrm{~K}$, respectively determined from the peak onset), which is comfortable high enough for future device application. Finally, the heating of 1 or its enantiopur counterparts does not induce any degradation or nitrogen inversion.

It is important to mention that kinetic investigations through ${ }^{1} \mathrm{H}$ NMR study cannot be performed in the case of $\mathbf{2}$ since the inversion takes place between two enantiomers that are hence indistinguishable from each other through NMR.

The kinetic investigations of the nitrogen inversion of $2 \mathrm{~N}_{R}$ into its enantiomer $2 \mathbf{N}_{\mathrm{S}}$ have therefore been performed by chiral HPLC in similar conditions than those above mentioned (in ethanol at $351.15 \mathrm{~K}$, Figure 4b). The inversion between the two enantiomers (from $2 \mathrm{~N}_{\mathrm{R}}$ to $2 \mathrm{~N}_{\mathrm{S}}$ ) provides very similar values ( $k=$ $0.0026 \mathrm{~min}^{-1}, \Delta G^{\neq}=115.9 \mathrm{~kJ} \mathrm{~mol}^{-1}$ and a half-life of inversion of $133 \mathrm{~min}$ ) than those exposed above for compound 3. Indeed, the phenyl ring in position 3 is too far from the nitrogen atom to have an influence on the kinetics of its inversion. Furthermore, 

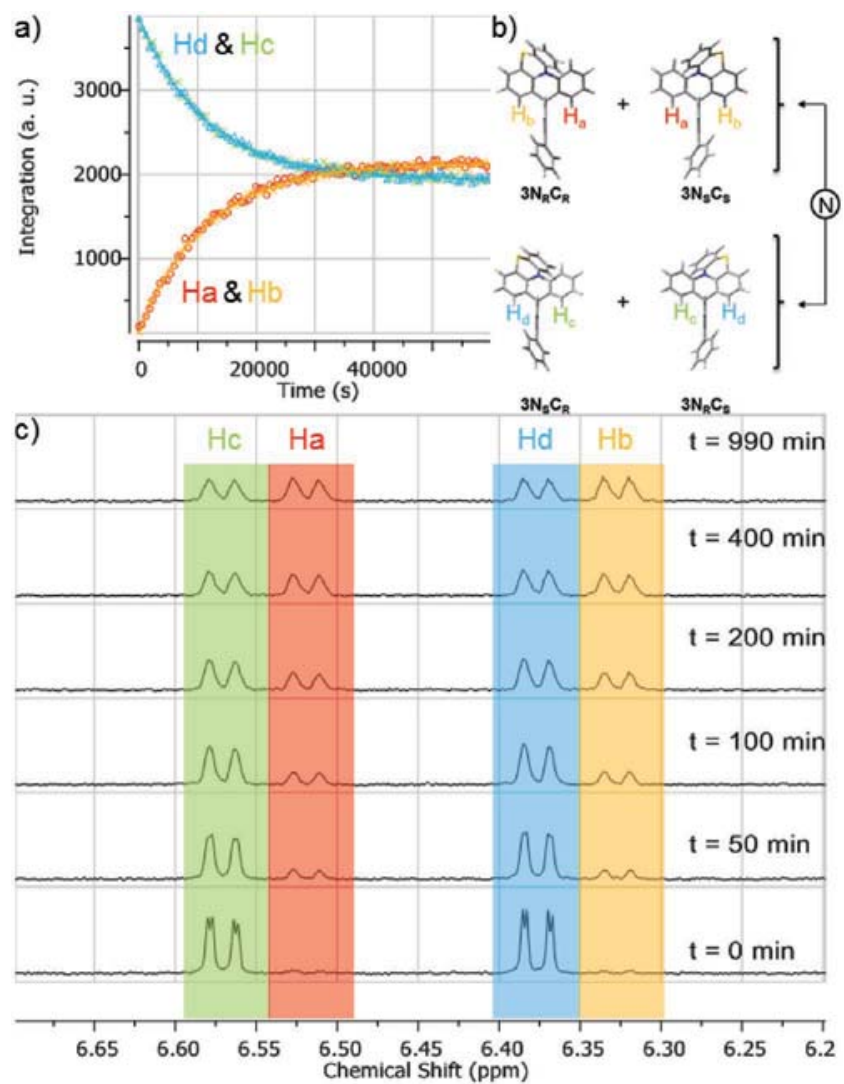

Figure 5. a) Evolution of the integration of $\mathrm{Ha}, \mathrm{Hb}, \mathrm{Hc}$, and $\mathrm{Hd}$ through time. b) Nomenclature of the investigated protons $\mathrm{Ha}, \mathrm{Hb}, \mathrm{Hc}$, and $\mathrm{Hd}$, c) Evolution of the ${ }^{1} \mathrm{H}$ NMR spectra of $3 \mathrm{~N}_{S} \mathrm{C}_{R}+3 \mathrm{~N}_{R} \mathrm{C}_{S}$ in DMSO- $d_{6}$ at $348 \mathrm{~K}$.

TGA investigations of 2 and $2 \mathrm{~N}_{\mathrm{R}}$ show decomposition temperatures recorded at $548 \mathrm{~K}$ for the racemic mixture and $500 \mathrm{~K}$ for the enantiopur $2 \mathrm{~N}_{\mathrm{R}}$ (see Figure S39 in the Supporting Information), again showing the effect of the packing mode on the stability. One can also note that these decomposition temperatures are lower than those exposed above for compounds $\mathbf{1}$ and $\mathbf{3}$, showing the influence of the pendant phenyl ring in raising the thermal stability. As for compound 3, the melting and glass transition temperatures could not be determined by DSC for each enantiopur form because of the nitrogen inversion (Figures S42 and S43, Supporting Information).

Finally, the mechanism of the nitrogen inversion has been studied by theoretical calculations. Thus, the molecular structures of the two enantiomers of 2 in their ground state and planar-shaped transition state, corresponding to the nitrogen inversion process, were modelled (Figure 7a). Nitrogen torsion angles were calculated at $165^{\circ}$ for $2 \mathrm{~N}_{\mathrm{R}}, 180^{\circ}$ for the transition state and $195^{\circ}$ for $2 \mathrm{~N}_{\mathrm{S}}$. The nitrogen inversion leaves the fluorene unchanged, whereas the curvature of the acridine part is reversed and the phenyl of the phenothiazine unit moves from below to above the mean plane of the acridine. Thus, the theoretical-free energy change along the nitrogen inversion of 2 was evaluated at $121.0 \mathrm{~kJ} \mathrm{~mol}^{-1}$ (see Figure S20 in the Supporting Information for the plot of the theoretical-free energy change against the nitrogen torsion angle). This feature being a)

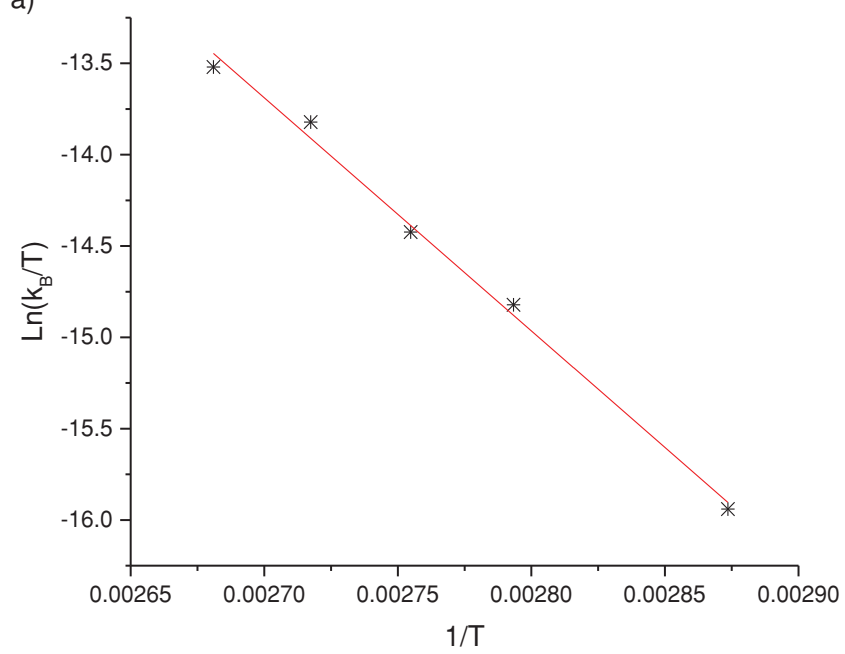

b)

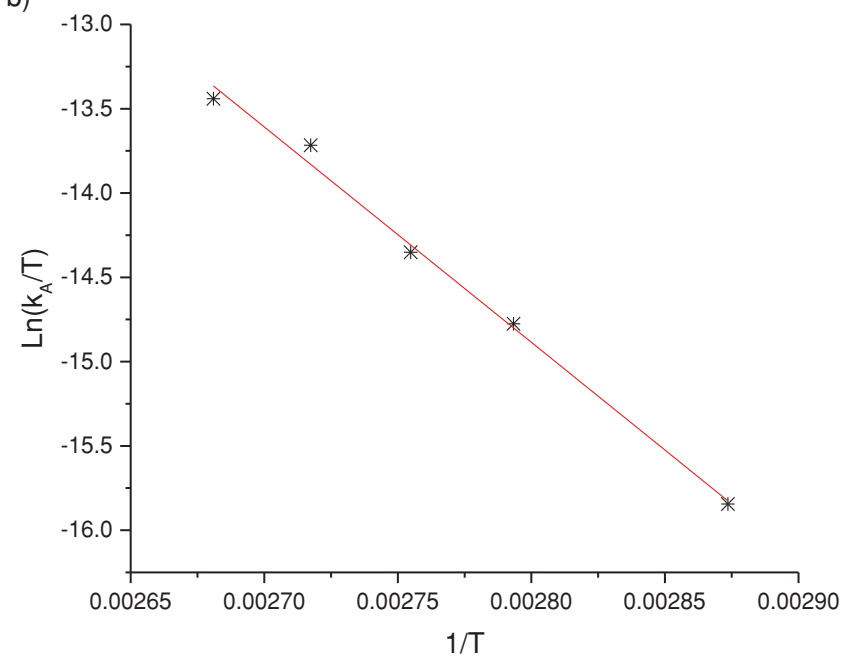

Figure 6. Evolution of $\operatorname{Ln}(k / T)$ in function of $1 / T$ a) for $3 N_{S} C_{R}+3 N_{R} C_{S}$ and b) for $3 N_{R} C_{R}+3 N_{S} C_{S}$.

at the origin of the chirality of QPTZ, the transition state corresponding to the conversion of $3 \mathbf{N}_{R} C_{R}$ (nitrogen torsion angle of $194^{\circ}$ ) into $3 \mathrm{~N}_{\mathrm{S}} \mathrm{C}_{\mathrm{R}}$ (nitrogen torsion angle of $166^{\circ}$ ) has also been modelled according to the same procedure (Figure $7 \mathrm{~b}$ and see Figure S28 and S29 in the Supporting Information). The nitrogen inversion barrier is thus evaluated at $120.4 \mathrm{~kJ} \mathrm{~mol}^{-1}$ from $3 N_{R} C_{R}$ and $120.0 \mathrm{~kJ} \mathrm{~mol}{ }^{-1}$ from $3 N_{S} C_{R}\left(3 N_{R} C_{R}\right.$ being stabilized by $0.4 \mathrm{~kJ} \mathrm{~mol}^{-1}$ compared to $3 \mathrm{~N}_{\mathrm{S}} \mathrm{C}_{\mathrm{R}}$ as experimentally observed). Therefore, experimental and theoretical data are in good agreement and provide similar values for both 2 and 3 , highlighting that the presence of the phenyl ring on the fluorene backbone in position 3 has no influence on the nitrogen inversion but induces the formations of the diastereoisomers.

\section{Conclusion}

To conclude, this work presents the first examples of optically pure QPTZ-based molecules. In these systems, the flipping 
a)

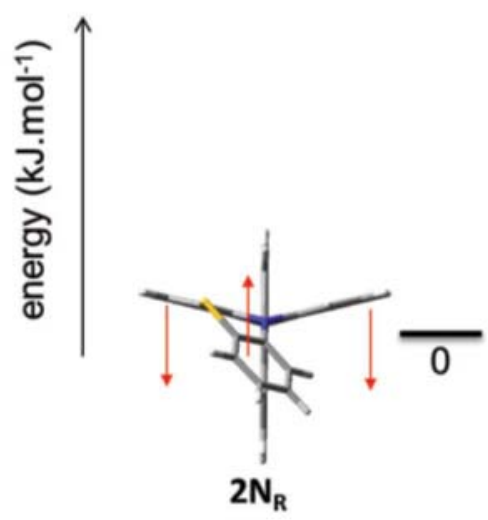

b)

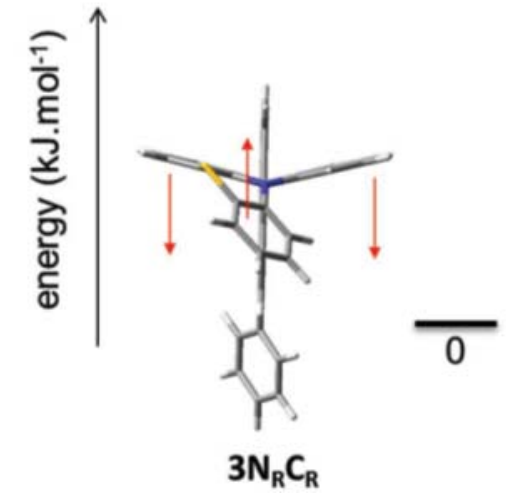

TS
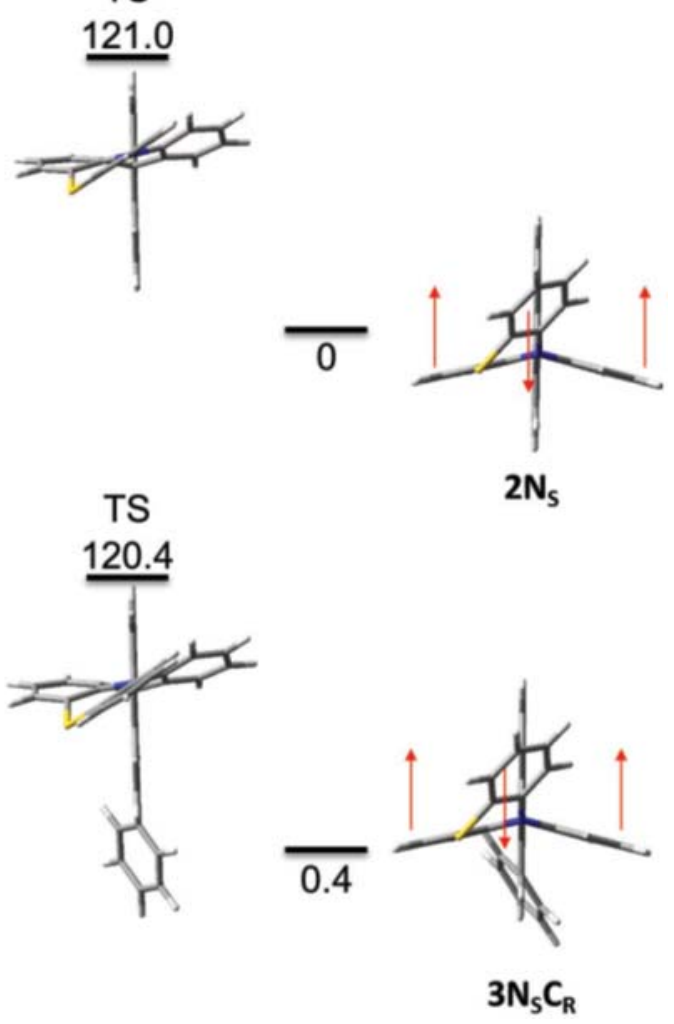

Figure 7. Calculated structures of a) $2 N_{R}$ and $2 N_{S}$ and b) $3 N_{R} C_{R}$ and $3 N_{S} C_{R}$ and their transition states of $N$ inversion in ethanol and the variation of free energy at $351.15 \mathrm{~K}$ under $1 \mathrm{~atm}(\mathrm{~B} 3 \mathrm{LYP} / 6-31 \mathrm{~g}(\mathrm{~d}, \mathrm{p}))$. TS = transition state.

of the phenothiazine unit leads to a nitrogen inversion with a high barrier energy $\left(\approx 115 \mathrm{~kJ} \mathrm{~mol}^{-1}\right.$ at $\left.351.15 \mathrm{~K}\right)$, which allows to successfully isolate each isomer at room temperature. Constraining the nitrogen atom in a pyramidal configuration appears hence as an efficient strategy to generate enantiopure compounds. In addition, the introduction of a phenyl ring in position 1 of the fluorene completely prevents the flipping of the phenothiazine and hence the formation of the other pair of enantiomers providing an efficient diastereocontrol. As the efficiency of the QPTZ fragment has recently been highlighted in phosphorescent OLEDs (and is therefore an interesting candidate for other organic electronics applications), ${ }^{[5]}$ we believe that the present work may open new avenues in the use of this electron-rich fragment in its chiral form.

\section{Acknowledgements}

The authors thank the CDIFX and CRMPO (Rennes) for X-ray data collection and mass spectrometry, respectively. This work was granted access to the computing resources of CINES (Montpellier, allocation 2017-A0020805032 awarded by GENCI). The ANR14-CE05-0024 was warmly thanked for financial support and for a post-doctoral position
(C.Q.) and for a PhD grant (L.S.). The authors also thank Dr L. Favereau (Rennes) for fruitful discussions.
[1] J. R. Brandt, F. Salerno, M. J. Fuchter, Nat. Rev. Chem. 2017, 1, 0045.

[2] a) J. R. Brandt, X. Wang, Y. Yang, A. J. Campbell, M. J. Fuchter, J. Am. Chem. Soc. 2016, 138, 9743; b) Y. Geng, A. Trajkovska, S. W. Culligan, J. J. Ou, H. M. P. Chen, D. Katsis, S. H. Chen, J. Am. Chem. Soc. 2003, 125, 14032; c) Y. Yang, R. C. da Costa, D.-M. Smilgies, A. J. Campbell, M. J. Fuchter, Adv. Mater. 2013, 25, 2624; d) F. Zinna, U. Giovanella, L. D. Bari, Adv. Mater. 2015, 27, 1791; e) C.-F. Chen, M. Li, S.-H. Li, D. Zhang, M. Cai, L. Duan, M.-K. Fung, Angew. Chem., Int. Ed. 2018, 57, 2889.

[3] a) Y. Yang, B. Rice, X. Shi, J. R. Brandt, R. Correa da Costa, G. J. Hedley, D.-M. Smilgies, J. M. Frost, I. D. W. Samuel, 
A. Otero-de-la-Roza, E. R. Johnson, K. E. Jelfs, J. Nelson, A. J. Campbell, M. J. Fuchter, ACS Nano 2017, 11, 8329; b) Y. Yang, R. C. da Costa, M. J. Fuchter, A. J. Campbell, Nat. Photonics 2013, 7, 634; c) T. Hatakeyama, S. Hashimoto, T. Oba, M. Nakamura, J. Am. Chem. Soc 2012, 134, 19600.

[4] a) P. Josse, L. Favereau, C. Shen, S. Dabos-Seignon, P. Blanchard, C. Cabanetos, J. Crassous, Chem. - Eur. J. 2017, 23, 6277; b) A. Seki, Y. Funatsu, M. Funahashi, Phys. Chem. Chem. Phys. 2017, 19, 16446.

[5] C. Poriel, J. Rault-Berthelot, S. Thiery, C. Quinton, O. Jeannin, U. Biapo, D. Tondelier, B. Geffroy, Chem. - Eur. J. 2016, 22, 17930.

[6] a) M. Romain, D. Tondelier, B. Geffroy, A. Shirinskaya, O. Jeannin, J. Rault-Berthelot, C. Poriel, Chem. Commun. 2015, 51, 1313;

b) M. Romain, D. Tondelier, O. Jeannin, B. Geffroy, J. Rault-Berthelot,

C. Poriel, J. Mater. Chem. C 2015, 3, 9701; c) M. Romain,

D. Tondelier, B. Geffroy, O. Jeannin, E. Jacques, J. Rault-Berthelot,

C. Poriel, Chem. - Eur. J. 2015, 21, 9426.

[7] a) J. M. Lehn, Dynamic Stereochemistry, Springer, Berlin, Heidelberg 1970 , p. 311 ; b) P. Kaszyński, A. Kłys, S. Domagała, K. Woźniak, Tetrahedron 2017, 73, 3823; c) K. Ramig, G. Subramaniam, S. Karimi, D. J. Szalda, A. Ko, A. Lam, J. Li, A. Coaderaj, L. Cavdar, L. Bogdan, K. Kwon, E. M. Greer, J. Org. Chem. 2016, 81, 3313.

[8] M. Ōki, Topics in Stereochemistry (Eds: N. L. Allinger, E. L. Eliel, S. H. Wilen), Vol. 14, John Wiley \& Sons, Inc. 1983, p. 1.
[9] a) C. Wolf, Dynamic Stereochemistry of Chiral Compounds: Principles and Applications, RSC Publishing, 2008; b) J. Bjorgo, D. R. Boyd, J. Chem. Soc., Perkin Trans. 2 1973, 0, 1575; c) R. G. Kostyanovsky, G. K. Kadorkina, V. R. Kostyanovsky, V. Schurig, O. Trapp, Angew. Chem., Int. Ed. 2000, 39, 2938; d) F. Montanari, I. Moretti, G. Torre, J. Chem. Soc. D: Chem. Commun. 1969, 19, 1086; e) A. M. Belostotskii, H. E. Gottlieb, M. Shokhen, J. Org. Chem. 2002, 67, 9257; f) A. M. Belostotskii, H. E. Gottlieb, A. Hassner, J. Am. Chem. Soc. 1996, 118, 7783.

[10] S. Thiery, D. Tondelier, B. Geffroy, O. Jeannin, J. Rault-Berthelot, C. Poriel, Chem. - Eur. J. 2016, 22, 10136.

[11] a) Y.-K. Wang, S.-F. Wu, Y. Yuan, S.-H. Li, M.-K. Fung, L.-S. Liao, Z.-Q. Jiang, Org. Lett. 2017, 19, 3155; b) Y.-K. Wang, Q. Sun, S.-F. Wu, Y. Yuan, Q. Li, Z.-Q. Jiang, M.-K. Fung, L.-S. Liao, Adv. Funct. Mater. 2016, 26, 7929; c) Y. K. Wang, S. H. Li, S. F. Wu, C. C. Huang, S. Kumar, Z. Q. Jiang, M. K. Fung, L. S. Liao, Adv. Funct. Mater. 2018, 28, 1706228.

[12] a) V. Alcazar, F. Diederich, Angew. Chem., Int. Ed. 1992, 31, 1521; b) X. Cheng, Q. Zhang, J. H. Xie, L. X. Wang, Q. L. Zhou, Angew. Chem., Int. Ed. 2005, 44, 1118; c) C. Poriel, Y. Ferrand, P. Le Maux, J. Rault-Berthelot, G. Simonneaux, Synth. Met. 2008, 158, 796.

[13] P. R. Andrews, S. L. A. Munro, M. Sadek, M. G. Wong, J. Chem. Soc., Perkin Trans. 2 1988, 0, 711.

[14] L. Sicard, C. Quinton, J.-D. Peltier, D. Tondelier, B. Geffroy, U. Biapo, R. Métivier, O. Jeannin, J. Rault-Berthelot, C. Poriel, Chem. - Eur. J. 2017, 23, 7719. 